OPEN ACCESS

Edited by:

Xingxing Zhang,

Dalarna University, Sweden

Reviewed by:

Neeraj Dhanraj Bokde, Aarhus University, Denmark

Puneet Saini,

Dalarna University, Sweden

${ }^{*}$ Correspondence: Ketshephaone Keisang ketshephaone.keisang@

studentmail.biust.ac.bw

Specialty section:

This article was submitted to Sustainable Energy Systems and Policies,

a section of the journal Frontiers in Energy Research

Received: 24 June 2021 Accepted: 17 September 2021 Published: 05 November 2021

Citation: Keisang K, Bader T and Samikannu R (2021) Review of Operation and Maintenance Methodologies for Solar

Photovoltaic Microgrids.

Front. Energy Res. 9:730230. doi: 10.3389/fenrg.2021.730230

\section{Review of Operation and Maintenance Methodologies for Solar Photovoltaic Microgrids}

\author{
Ketshephaone Keisang ${ }^{1 *}$, Tobias Bader ${ }^{2}$ and Ravi Samikannu ${ }^{3}$ \\ ${ }^{1}$ Department of Mechanical, Energy and Industrial Engineering, Botswana International University of Science and Technology, \\ Palapye, Botswana, ${ }^{2}$ European Campus Rottal-Inn, Deggendorf Institute of Technology, Deggendorf, Germany, ${ }^{3}$ Department of \\ Electrical Computer and Telecommunications Engineering, Botswana International University of Science and Technology, \\ Palapye, Botswana
}

Global concerns and growth in electricity demand, especially for rural and remote settlements, has forced governments, scientists, engineers, and researchers to look for alternative solutions in the form of renewable energy sources. High global growth in solar energy technology applications has added more weight in operations and maintenance (O\&M) of solar-photovoltaic (SPV) systems. SPV reliability and optimized system performance are key to ensuring success and continual adaptation of SPV technology. O\&M plays a central role in ensuring sustainability and long-term availability throughout the operational lifetime of the elements of SPV systems whilst boosting confidence of ultimate consumers in solar energy. While appreciating that SPV installations intrinsically require minimal maintenance actions, the objective of this manuscript is hence to reaffirm the significance of O\&M scheduling in SPV systems by reviewing the O\&M approaches in SPV microgrid systems. Further discussions focus on the various maintenance strategies employed in the field with special emphasis on corrective, preventive, and predictive maintenance strategies. Because of the variation in the design and development procedures of SPV systems, there is lack of clear steps followed in the development of an O\&M program for SPV systems and the evaluation of its performance. This manuscript serves to address this through a model for developing an O\&M program and portrays the key elements for its success, including a management and execution approach for improved risk-return balance and savings from the O\&M expenditure. Eventually, the three models of executing an O\&M program (i.e., in-house O\&M team, third party contract, or installation company) are analyzed.

Keywords: solar photovoltaics, microgrids, sustainability, operation \& maintenance, maintenance management \& strategies

\section{INTRODUCTION}

\section{Motivation and Background}

The majority of the population in Sub-Saharan Africa are without access to clean electricity amongst other basic human amenities, with most of the population located far from the conventional power grid. This means that poverty is at its highest in these developing countries due to lack of power, which could be the key driver to economic transformation. 
Decentralized generation sources through microgrids have emerged as a means of generating and utilizing power locally. Efforts to deliver power through SPV microgrids has met a rather unanticipated halt due to comparably low lifetime in the field, bringing into question their reliability and effectiveness. The main problems identified were classified as: design, planning and management issues, O\&M, market constraints, lack of skills \& knowledge, and policy frameworks. This is supported by a number of studies (Case and Ketlogetswe 2016; Akinyele, Belikov, and Levron 2018; Njoh et al., 2019). It is important to address these to benefit from the many advantages brought by microgrids.

The continuous population growth, as well as expansion in industrial activities, has created an exorbitant energy demand. Conventional power generation methods have also become illfated due to the issues of global warming and environmental pollution they render and, coupled with the depletion they are facing, are non-renewable in nature (Machrafi 2012). Renewable energy applications are gaining support and recognition in the quest for decarbonization of the energy sector and reducing carbon emissions since they are unlimited and naturally replenished (Messenger and Yogi Goswami, 2015; Kale 2016). SPVs are one of the fastest growing forms of renewable energy generation in terms of development and technology advancement. According to a report on "Future of Photovoltaics" by International Renewable Energy Agency (IRENA), the SPV installation capacity has increased from $40 \mathrm{GW}$ to a massive $583.5 \mathrm{GW}$ within the span of 10 years (International Renewable Energy Agency-IRENA 2019). This is consistent with the work of Gentries (Bradford 2006) on the evolution of solar PV technology dissemination. The author argues that, due to the recent intensification of research and development on SPV technologies to yield cost-effective and feasible energy solutions, SPV applications are tipped to take over domestic and commercial markets. This, however, is reliant on reliability and optimum system performance, specifically energy yield, which is pivotal to ensuring the success and continual deployment of SPV technology, whether for small-scale or for utility grid applications (Jahn 2003).

In its nature, SPV power generation is surrounded by uncertainty due to intermittency issues, hence giving rise to specific operational and planning problems. This uncertainty means that when forecasting energy yield, accurate data is needed to produce reliable and dependable estimates (Ventura and Tina 2016). While solar microgrids may intrinsically be lowrisk systems as compared to the conventional power generation setups, they are subject to unique risks associated with financial, operational, and technical aspects (Baurzhan and Jenkins 2016). Regular problems in SPV systems emerge as reduction in efficiency and output deficit stemming from faulty events. These therefore prompt diligent and thorough inquiries on possible fault types, failure mechanisms, as well as detection and classification to perform remedial actions. Research is abound with studies pertaining to fault analysis in SPV systems as a necessary evil to protect system components from catastrophic failure (Zhao et al., 2013; Haque et al., 2019) with various fault localization and detection techniques developed (Chine et al., 2014; Silvestre et al., 2014; Zhao et al., 2015; Dhimish et al., 2017; Harrou et al., 2019).

Tragic experiences emanating from faulty conditions in SPV systems have been studied in the past. In previous research (Eltawil and Zhao 2010; Kandpal et al., 2016) an assessment of PV module failure was carried out, identifying some of the common fault scenarios including potential induced degradation, cell cracks, and encapsulant discoloration. The understanding of faults and failure modes plays a critical role in deciding the best method to employ in dealing with the situation to prevent further or impending catastrophe (Osmani et al., 2020). To deal with this, sensors, control, and protection devices are hence installed and incorporated in the system for monitoring purposes as well as facilitating the smooth functioning of the network (Louie 2018). Various research has been carried out to address these various topics relating to the general approach to SPV microgrids' operation at a high level and careful scrutiny with emphasis on areas of optimization of system design and energy production forecasting, system performance, reliability, and safety (Tahri et al., 2013; Allamehzadeh 2017; Dhillon 2017; Oprea et al., 2019) as well as operation and maintenance (C 2010; Paul and Bray 2012; Woyte and Goy 2017; United States Agency for International Development 2013).

The incentives and policies in various countries have also put more weight on the need for performance assurance, which is warranted by adaptation of standardized and pertinent O\&M approaches in SPV systems. Moreover, this standardized approach facilitates planning and decision making as well as much needed guarantee of sustainability and long-term impacts by key players or stakeholders in the SPV microgrid industry (Lynn 2005). The approach comprises of a maintenance strategy with clear techniques, measures, and procedures to ensure maximum system availability and ongoing optimal power generation. Maintenance strategies tend to be industry specific i.e., being better suited for particular kinds of equipment or machinery in that sector. The SPV industry encounters particular fault events, as has been highlighted. Therefore, a specialized maintenance strategy needs to be adopted to ensure stable and safe operation over the system lifespan of 20 years and beyond.

The significance of O\&M of SPV microgrids is discussed next, followed by a brief overview of the operation of solar photovoltaic microgrids in the next section, giving an idea of the general layout of the system and the main aspects of operations, i.e., planning maintenance strategies, supervision, and control as well as plant performance monitoring. This is followed by further discussions on the various maintenance strategies employed in the field: corrective maintenance, preventive maintenance, conditionbased maintenance, and predictive maintenance. Subsequently, attention is drawn to some key features and merits as well as limitations of each stratagem to stress out the serious decisions required in selection of which approach to adopt. More work is reviewed on the elements of a successful O\&M program and the way to go about developing it. The review then proceeds to look at the three models of executing an operation and maintenance program: In-house O\&M team, Third Party Contract (O\&M 


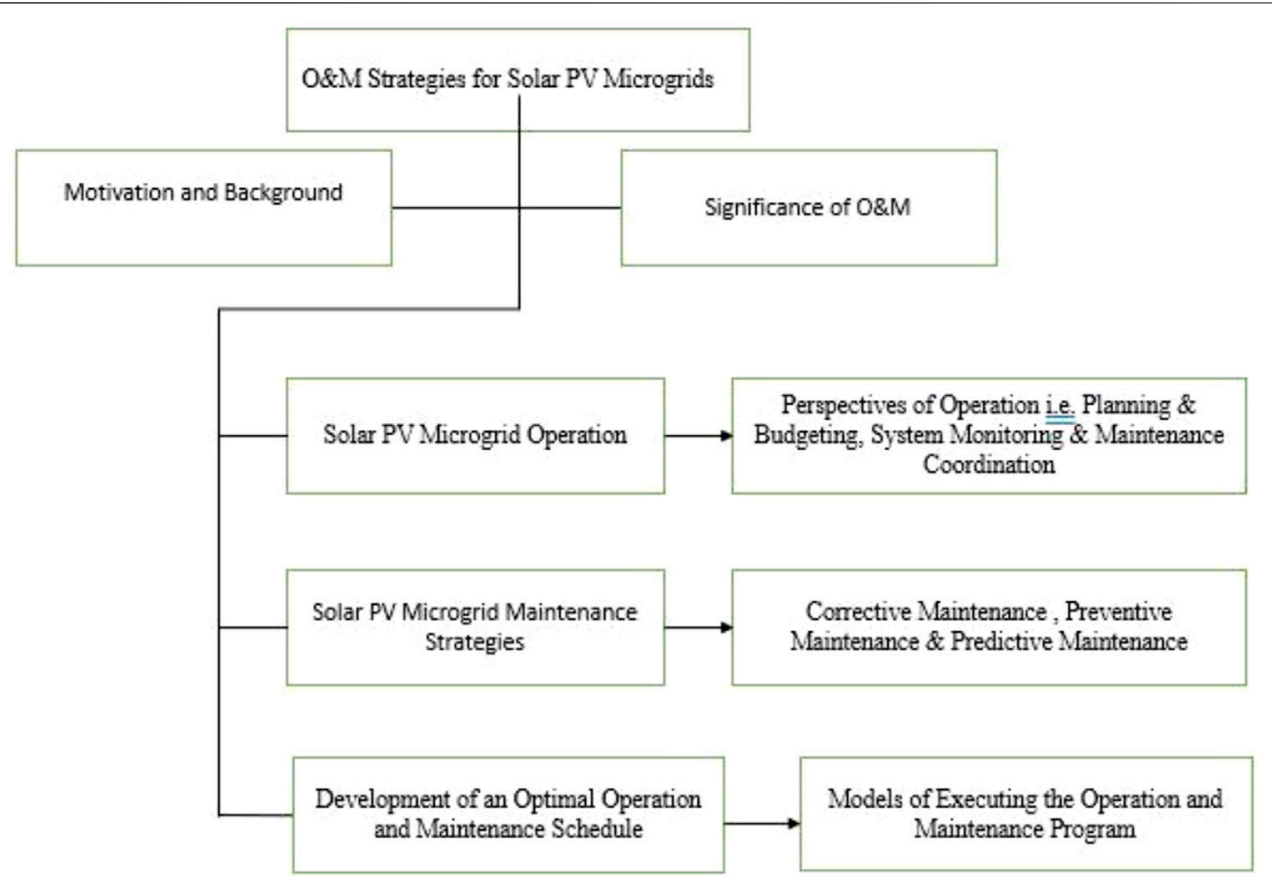

FIGURE 1 | Structure of the Manuscript.

service company), or Installation company (EPC company). Finally, a conclusion is made, and future works are put into perspective. Figure 1 shows the structure of the manuscript.

\section{SIGNIFICANCE OF OPERATION AND MAINTENANCE}

Owing to the intermittency and variability of solar energy, an undisrupted operation is highly sought after, aiming to attain higher performance ratios. As such, this is one of the main objectives of having an O\&M program for PV installations. Pursuant to high growth in the development and deployment of solar photovoltaic technologies, maintenance practices are pertinent especially in commercial/industrial installations where reliability, efficiency in supplying power, safe system operation over the years, and return on investments are held critical. Maintenance forms the 'heart' of a successful SPV system. (Dhillon, 2017), defines maintenance as a set of organized activities and all actions necessary for retaining an item, or restoring to it, its functional and design stature. B. S. Dhillon categorizes and extensively explains and evaluates the various kinds of maintenance from preventive maintenance to corrective maintenance, predictive maintenance, and reliability centered-maintenance ("Solar System Safety and Maintenance" 2011).

Maintenance regimes are not only performance-centered but also play a huge role in terms of quality and safety assurance to customers (Chowdhury and Mourshed 2016). In the lifecycle of any solar PV project, operation and maintenance form the longest phase, meaning that special attention should be awarded to the planning, coordination of operational needs, and dispatch of maintenance actions(Mgonja and Saidi 2017; Villarini et al., 2017). That is, effective O\&M capabilities in solar technologies, as well as best practices in the field, are critical if there is to be reliability in harnessing the sun energy at a costeffective operation and for a prolonged period. Continual innovation and technology evolution necessitates adaptation in terms of operation practices and maintenance strategies that are aligned with modern-day shifts towards the power of data and cloud computing (Chebel-Morello et al., 2012; Imene Yahyaoui University Carlos III of Madrid 2018; Makala and Bakovic 2020).

Consequently, innovation has become a major ingredient upon which maintenance teams depend on to keep abreast with the changing market requirements. The competitiveness of SPV plants is centered around improving reliability and reducing maintenance and operating costs, as supported by previous research (Ventura and Tina 2016). Ventura and Tina (2016) applied data monitoring to get utility plant indices and models that recognize faults and avoid loss of yields to ensure high efficiency and availability. Research has proven that levelized costs of electricity would decline by $0.8 \%$ to $1.4 \%$ between 2015 and 2030, this being an improvement catalyzed by innovation in O\&M services (Emblemsvåg 2020; Iftikhar et al., 2021). Improvements in operating expenditure (OPEX) comprise huge portions of the savings. As such, well-designed O\&M models for SPV plants can improve the key performance indicators of SPV plants like power plant availability, annual average energy yield, and performance ratio, (Muñoz-Cerón et al., 2018; National Renewable Energy Laboratory NREL (2018)). In a nutshell, prudent maintenance planning and 


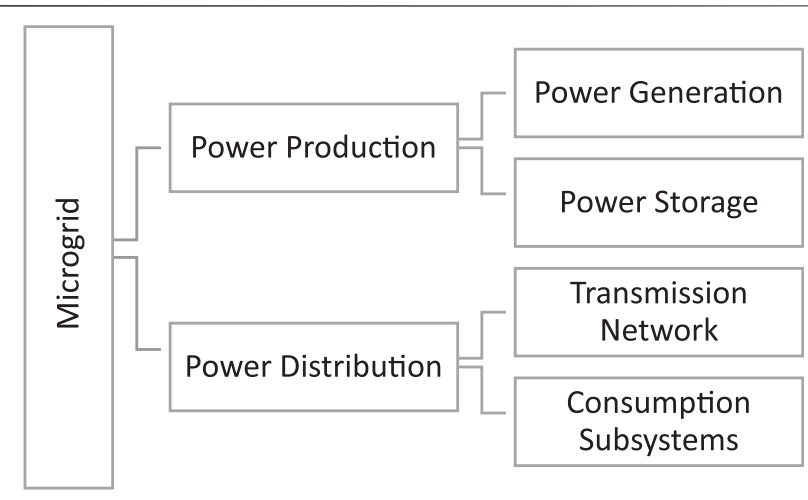

FIGURE 2 | Main aspects of a solar PV microgrid.

operational execution warrants positive financial returns for SPV installations. The financial returns are indirectly made through implementation of $s$ and robust system upkeep and corrective actions, which reduces expenditure on frequent repair of components.

\section{OVERVIEW OF SOLAR PHOTOVOLTAICS MICROGRIDS OPERATION}

\section{Microgrid}

The report by C. Marney \& Co. entitled "Microgrid evolution roadmap" defines a microgrid as "electricity distribution systems containing loads and distributed energy resources, that can be operated in a controlled, coordinated way either while connected to the main power network or while islanded" (Marnay et al., 2015). This definition portrays the characteristic features of the microgrid as described by Schnitzer et al. (2014), i.e. micro-grids are capable of generating power locally and supplying electricity to a relatively small number of users who are connected to each other through a shared distribution system. Essentially these serve as the main distinction between a standard SPV system, such as rooftop solar for an individual household, which is comprised of the basic SPV components. Furthermore, the high investment cost for a microgrid which includes the transmission through complex network cables, power modulation, and other power electronics for enhanced control and protection renders an extra requirement for operational and maintenance needs. The diverse microgrid architectures utilized in practice coupled with these seemingly passive components presents control issues associated with increased inspection and maintenance activities.

The SPVM operates as an isolated and autonomous power distribution network mostly for rural and remote community settings relying on solar as the main power source (Schnitzer et al., 2014). The system may be coupled with another source (usually diesel) as a backup or even battery power storage system (capital intensive) for uninterrupted power supply to the enduser (Katiraei et al., 2007). SPVM offer flexibility in the sense that it can take different configurational structures where there can be a central generation point or various points of generation in a household which serve as suppliers in different sectors of the area but combined into a single transmission network for demand management (Buchholz and Schwaegerl 2004; Hirsch et al., 2018). Figure 2 is a graphical representation of the main elemental aspects of a microgrid network based on functional classification. Portrayed by the block diagram is the characteristic features of a microgrid in general distribution systems, showing a microgrid as distinct from the rest of the system. It also displays s the power production resources and its ability to function exclusively without connectivity to a larger grid (Hirsch et al., 2018; Global Sustainable Energy Solutions GSES (2017)).

Nicholas. O, 2019, carried out a comparative study of DCversus AC-based microgrids. The study highlights the modularity of microgeneration systems as a great characteristic advantage in rural setup(microgrids) as it supports ease of modification in response to varying energy demands (Opiyo 2019a). SPV systems located on different houses can be integrated together through a web-like network microgrid. While this setup brings more reliability and robustness, this also comes with protection and control challenges associated with increased interconnections (Zhao et al., 2013). PV systems are like any other electrical power generating systems, as such, it is critical to follow the appropriate electrical standards, codes and principles of operation and interfacing when developing these microgrid networks for safety and reliability (Argetsinger and Inskeep 2017; Forum, Economic, 2020).

\section{Typical Setup of a Solar Photovoltaics Microgrid}

A solar PV system as depicted in Figure 3 is a synergy of individual components which includes solar panels, charge controller, battery (power storage), charge controller, inverter and power transmission cables, as well as electrical loads (appliances) (Ali et al., 2019). There are various ways in which to connect the components to supply the consumers/loads; this is referred to as network topology (Sebitosi et al., 2006). Illustrated in Figure 4 are the variable ways of connection that reflect the flexibility of setting up the network depending on the geography of the settlement, need to separate out loads of different priority, the resources, or the anticipated operation model (Bhattacharyya and Palit, 2014).

According to Goswami, the lack of motorized equipment in SPV systems renders them anti-operation and maintenance free, but that is not actually the case (Goswami and Kreider 2001; Messenger and Yogi Goswami, 2015). SPV systems are subject to various faults leading to power losses and consequently lack of returns on investment. Essentially, solar power generation needs to be tapped on to the highest order i.e., maximum energy yield and efficient performance when solar is available because of its dependence on weather conditions (Paul and Bray 2012; Allamehzadeh 2017) The smooth flow and operation of SPV systems is made possible through the use of control and protection devices (Park et al., 2009; Yang et al.,2014; Salman et al., 2018). Their function also encompasses detection and isolation of faulty components from the system, thereby minimizing energy losses and improving the power supply robustness and system reliability in general (Gokmen et al., 


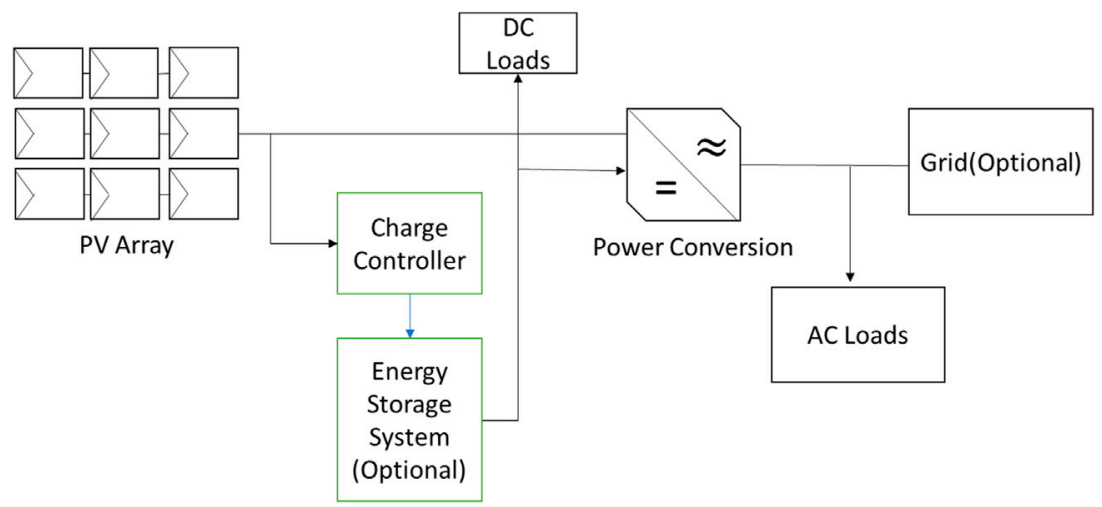

FIGURE 3 | General solar PV System components (Justo et al., 2013; Kumar et al., 2017).

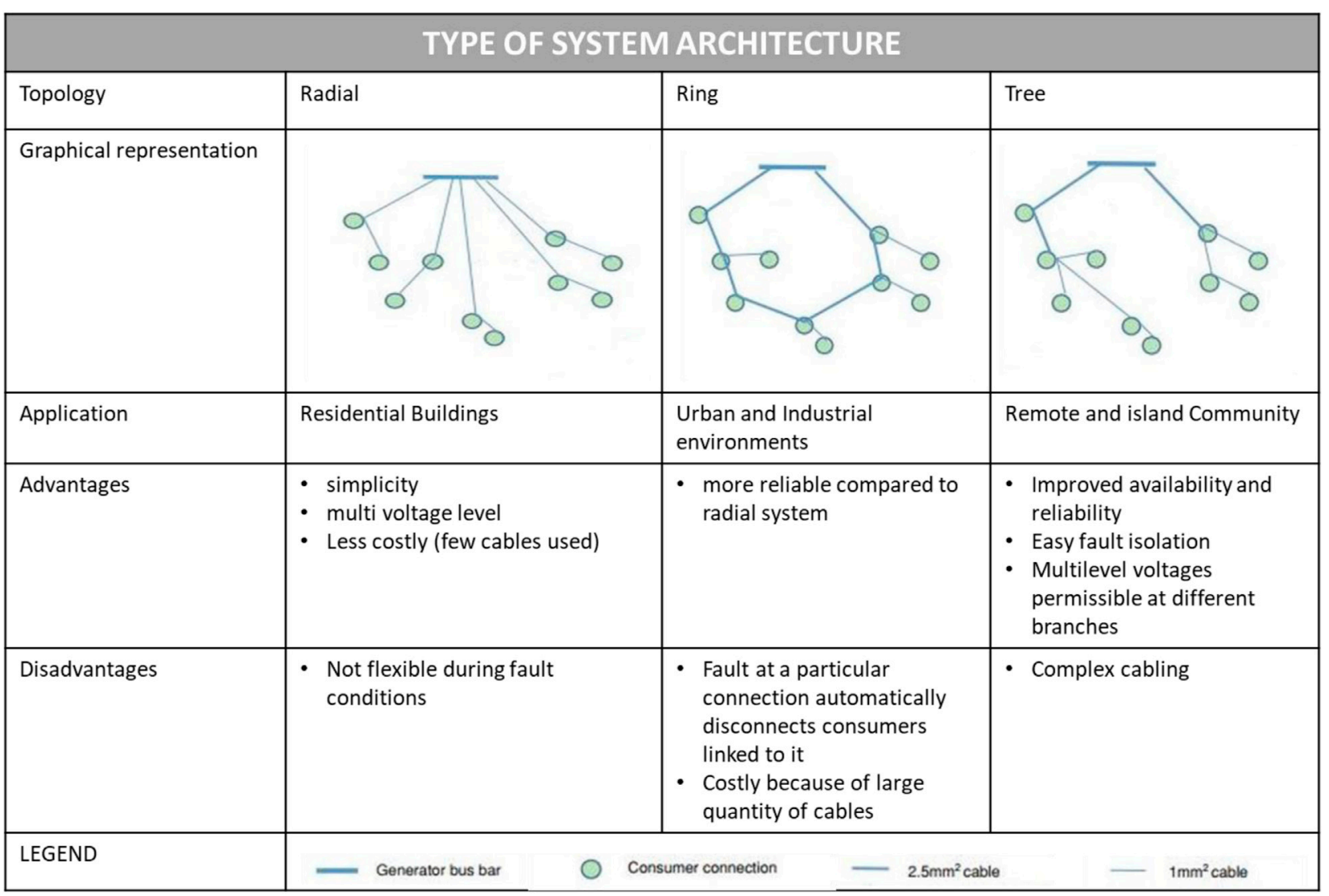

FIGURE 4 | Microgrid topologies applicable to offgrid PV setting Adopted from [29][38][39].

2012; Alam et al., 2015). Data acquisition is a fundamental aspect in tracking optimum operation, energy generation forecasting, and optimization of system performance MPPT. This could be real-time system data or historical performance data utilized in achievement of various objectives and making informed decision (Drews et al., 2007; C 2010). In radial configuration, the DC bus supplies power to the loads through a single path, usually where there are low voltage demands to avoid extra conversion stages. There is also the ring configuration, also termed loop network, whereby there are multiple paths between the source (DC bus) and the consumer, whereas in a tree configuration the paths of power from the DC bus forms branch-like lines before further spreading to different loads connected to them (Kumar et al., 2017; Asian Development Bank 2020). 


\begin{tabular}{|l|l|l|}
\hline Planning \& Budgeting & System Monitoring & O\&M Coordination \\
\hline $\begin{array}{c}\text { Equipment inventory } \\
\text { Management }\end{array}$ & $\begin{array}{c}\text { Keeping track of system } \\
\text { condition }\end{array}$ & $\begin{array}{c}\text { Performance } \\
\text { Assessment }\end{array}$ \\
\hline $\begin{array}{c}\text { Curation of AS-built } \\
\text { diagrams }\end{array}$ & Performance Reporting & Work order \\
\hline Contracting & System status reviews \\
\hline FIGURE 5 | Integral aspects in operation of solar PV fleet Solar Power Europe [SPE] 2018.
\end{tabular}

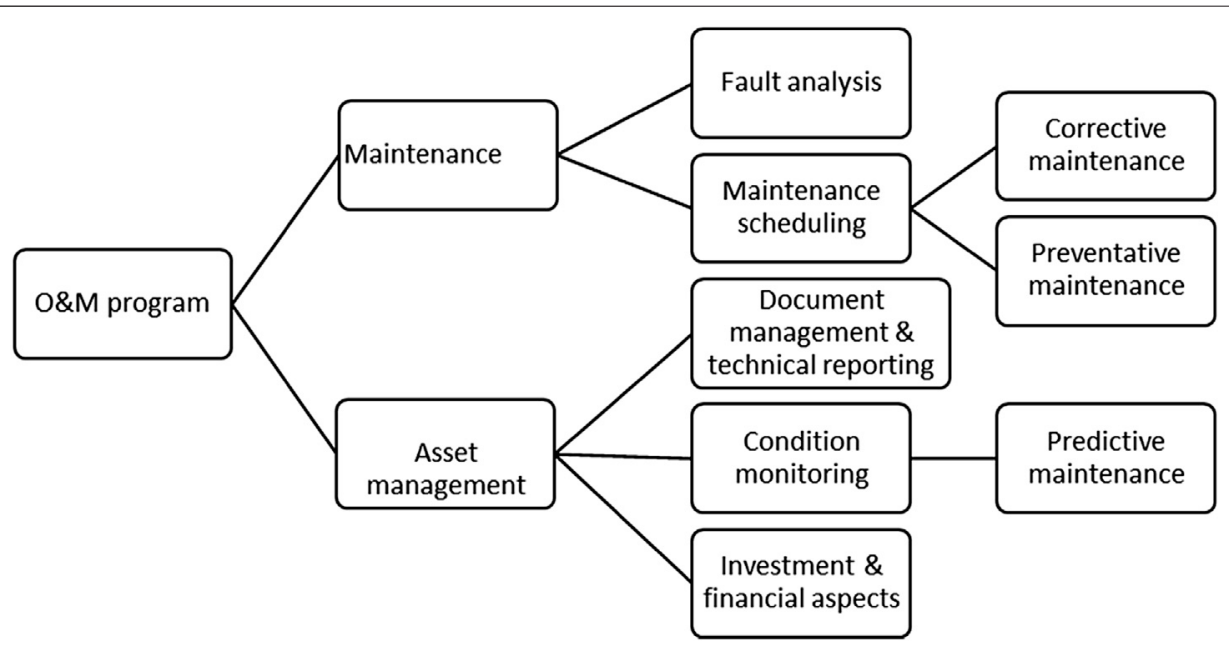

FIGURE 6 | Schematic for the main aspects of a maintenance program (Eltawil and Zhao 2010; Hirsch et al., 2018).

\section{Perspectives of Solar Photovoltaics Plant Operation}

According to (British Standards Institution BSI, (2010)) - BS EN 13306:2010, system operation is referred to in clause 2.9 as "The combination of all technical and administrative actions intended to enable an item to perform a required function", recognizing necessary adaptation to changes in external conditions. Operations of solar PV microgrids encompass some key processes which complement or work together for the optimal system upkeep, reliable power supply, and improved system efficiency while achieving system longevity and reduction in maintenance costs. These are monitoring (remote or onsite), supervision and control, and planning and coordination of maintenance strategies (Practices and Version, n.d.). A summary of the diverse viewpoints to SPV plant operations is portrayed in Figure 5.

\section{Operational Monitoring}

SPV power plants are, in most cases, unmanned and remotely supervised; therefore, remote monitoring is crucial for enhanced performance as well as reliability benefits (Tejwani et al., 2014). Operational monitoring is an essential part of the service life of SPV plants from system commissioning until the disposal stage or decommissioning phase. At this juncture performance monitoring serves to evaluate and analyze the working conditions of the solar PV installation to unearth and track down any design problems or anomalies in the system (Belhadj-Yahya 2010; Paul and Bray 2012). It can be said then that operation monitoring is a necessary ingredient for quality and safety assurance. Not only that, it is paramount in the optimization of output power since solar is susceptible to fluctuations due to weather and other unavoidable operational losses(BelhadjYahya 2010).

\section{Operational Modes}

By discussing the various microgrid modes or SPV system architectures and configurations, the implications-especially 
on the failure modes and ultimately the maintenance needs - are consequently unearthed for clarity in dealing with such.

\section{Classification or Categorization of Solar Photovoltaics Microgrids Operation Modes}

The most widely adopted and well-known manner of differentiating solar photovoltaic systems is according to their nature of connection or application type, i.e., whether the system operates on grid-tied mode, islanded(standalone) mode, or a hybrid setting. B. Zhao et al., (B. Zhao et al., 2017), through an analytical model simulation in MATLAB, presents a practical approach to elaborate design and control of the two microgrid configurations of distributed solar PV networks. Standalone Solar Home Systems and Microgrid, Grid Tied solar PV Systems, and Hybrid PV Systems represent types of microgrids set apart by their control topology, network parameters like capacity including loads type, and their micro-source connectivity principle (Asuamah et al., 2021).

Microgrids can be classified on a business model criterion based on the profit motive of the system. SPV plant O\&M needs and actions are key budgetary items, therefore the impacts of system faults have a more direct impact on the cash flows. The developer has to choose a business model that will meet the long term success goals and financial viability to insure and cater for O\&M expenses, which is crucial in electricity supply reliability (Schnitzer et al., 2014). The For-Profit (FP) model as denoted by the name is a microgrid operational setup which aims to generate more revenue so that investment and all overhead costs are recovered. Partly Subsidized Non-Profit (PSNP) is a model where a considerable portion of investments are subsidized, while the general upkeep costs are covered through tariffbased income. Conversely, the Fully Subsidized Non-Profit (FSNP) models operate more like charity projects without capital recovery, but the O\&M needs uses in-kind labor contributions from the project benefactors for non-technical maintenance, depending on subsidies or external aid for the rest.

Another means of categorization of SPV microgrids is based on the control architecture being utilized in the installation. Thomas M. and co, 2016 (Morstyn et al., 2016), undertook a study on AC and DC microgrid systems, focusing on their operation and control, particularly on how structural configuration, microgrid control, and power management of these systems affect the role they play in rural electrification. The authors made an extensive comparative study that evaluated the economic advantage of solar PV microgrids based on whether the system is DC-based or AC coupled (Opiyo 2019b). These strategies are inspired by the need for robustness in power delivery plus flowless communication networks which are integral in system monitoring. Further discussions are made on the role of energy storage, demand side management (DSM), and PV output power regulation in the ultimate system's operational layout. One more perspective in terms of microgrid operation is based on whether it utilizes a centralized or decentralized approach.

In all this classification it is vital to acknowledge that, whatever the operational principle, control strategy employed in the microgrid and their business model, the actual consequence at the core is this directly influences the maintenance and general system upkeep requirements. Majumder (2013) studies stability issues in microgrid networks by categorizing the problems with three types of microgrids: campus microgrid, utility microgrid, and remote microgrid. As such, specific attention is given to the technical experience and skills required when dealing with microgrids.

Some studies have (Wireman 2015; National Renewable Energy Laboratory NREL (2018)) discussed issues of SPV microgrid stability issues. It is highlighted that the complexity of the equipment, the skills of the operators, or IPP regulations and the rest of stakeholder participation are some key determining factors of the degree of procedures and measures utilized in the operation of microgrids. Stability in SPV microgrids is also discussed Majumder (2013) by looking at small signal, transient, and the voltage stability aspects of remote, utility connected, and facility microgrids, outlining the role of microgrid topology, control strategy, and mode of operation as key aspects that need careful examination. Further challenges in microgrids are safety-related mishaps, which affect both operators and the system status.

Reliability and resiliency of microgrids is at the forefront of discussions, roadmaps, and plans on equitable energy transition. Concerns are focused on the ability of renewable-based microgrids to sustainably supply power with fewer interruptions. This is embedded on the operation principles of the microgrid. Briefly put, operation in SPV microgrids serve as a lifeline, being critical in ensuring long service life for the various system components. Therefore, understanding the functionality of the components that make up the SPV microgrid is an important aspect. Essentially, the main aspects of an SPV microgrid according to function are power production (PV Modules), power transmission and distribution (cabling, breakers, and connectors), and storage (optional). SPV microgrids are designed to meet the electricity demands of varying quantities and different end-use requirements; this gives rise to the distinct configurations or network architectures. Consequently, there are different types of SPV microgrids varied on the basis of application, the nature of connections, load type, control topology, etc. This classification can be referred to as operational modes of the microgrid as they dictate the principle with which the network is designed, controlled, and operated. In performing the necessary upkeep activities in the SPV microgrid there are three main aspects that needs consideration: planning and budgeting, system monitoring, and O\&M coordination. Successful operation of SPV microgrids hinges upon a dependable monitoring system in place which facilitates suitable system management and decision making for performance optimization.

\section{MAINTENANCE STRATEGIES}

Maintenance has become one of the critical aspects for improvement in service delivery across various industries while ensuring that safety and reliability are not compromised (Dhillon 2002). With regards to the SPV sector, due maintenance is essential in the realization of long service life of SPV installation, with low downtime thus proving sustainability and reliability in electricity generation and delivery to 
the end users (Thangaraj and Velury 2016). A survey carried out by Electric Power Research Institute (Epri 2010) underlines the pivotal role of pertinent O\&M practices as well as state of the art monitoring capabilities amidst the occurring SPV systems proliferation witnessed globally, arguing their necessity in enhancing long-term uptime, performance, and economic viability. The work presented responses from key stakeholders who are knowledgeable on aspects pertaining to O\&M activities and initiatives by SPV plant caretakers on O\&M measures, including making plans and scheduling and maintenance costing.

Maintenance strategies are geared towards avoiding deteriorating system performance resulting from potential faults. In their study (Hernández-Callejo et al.,2019), Luis HernándezCallejo and Co. carried out a review on photovoltaic systems with focus on system design and the operation and maintenance aspects. Highlighted in the review are the critical parts of the SPV system, the risks in operation and maintenance, as well as the factors affecting SPV system performance. The main point from this manuscript is that photovoltaic system design is the first step towards attaining high performances followed by optimal operation that brings about maximum energy yield and lastly maintenance which deals with any system malfunction and low generation output issues for high system efficiency and availability (Duttagupta and Singh 2006; Oprea et al., 2019).

The authors of Deli and Noel (2020); Epri (2010) classify strategies employed in maintenance as corrective, preventive, condition-based, and predictive maintenance, being characterized by opportunistic, focused-on-reliability, and production actions for system upkeep. The variation of these strategies is based on the distinct system efficiency, availability and components/system tradeoff, and mostly the owner performance goals (National Renewable Energy Laboratory NREL (2018)). Arsovski and Co. present a methodological approach that utilizes Balanced Score card inspired through a benchmark, assessing maintenance processes' effectiveness and its impact on the competitiveness of a business (Arsovski et al., 2011).It needs to be highlighted that financial implementation of maintenance interventions not only saves money through reducing system downtime but also saves on costly repairs (labour and components).

\section{Corrective Maintenance}

This maintenance strategy is also known as reactive maintenance; it entails unscheduled remedial actions undertaken to rectify failures, breakdowns, or any signs of inability to perform a function so as to restore a system or equipment to optimal performance (Dhillon 2017; Solar Power Europe [SPE] 2018).In a reactive mode, the promptness coming with being required to repair failure conditions results in diminutive attention paid to ensuring that the operating conditions are within the allowable specifications, resulting in the actual service performance and life-span of the equipment being compromised. It is a risky type of maintenance rendered by the fact that pressure may be on the maintenance team to return the system to normal operation quickly, giving them less planning time. Even though not planned for, in some instances corrective maintenance activities can be scheduled for during night or low irradiation hours to avoid interruption in system operation
(Myeni 2019; Woyte and Goy 2017). During repair works we normally consider whether to repair or replace. This decision relies on availability of replacement parts, lead time for replacement parts, cost of replacement parts, and difficulty and/or complexity of repair requirements. The primary goal of $\mathrm{CM}$ is to repair and restore equipment to its normal condition after failure has occurred.

\section{Preventive Maintenance}

Preventative Maintenance entails the precautionary steps undertaken for forestalling or lowering the probability of failure or an unacceptable level of degradation (Dhillon 2002).Scheduled maintenance is characterized by strategically planned, intervallic, and specific scheduled intervention measures to maintain equipment in the specified operating condition through the process of checking and reconditioning. Routine upkeep actions are carried out according to and with careful study of manufacturer's recommendation regardless of the actual performance and condition of the asset (Van Horenbeek et al., 2013). A critical aspect that needs careful attention with this strategy is the ideal length and time for maintenance intervals and the actions that may be performed at variable, systematic, or based on the condition of the system(Alam et al., 2015; Baklouti et al., 2020). Systematic preventive maintenance is characterized by replacing aging or unfit components according to a predetermined interval. The condition-based maintenance approach is carried out subject to the state of the components i.e., when signs of incipient failure or abnormal performance are observed. Even issues of performance from aging can prompt components' replacement (Sharma and Chandel 2013). In their study Said and Walwil (2014), undertook a study on the dust fouling factors on PV modules performance, showing a reduction in spectral transmittance at 30\% representing irradiance to the cells and hence less power conversion. As proactive measures, the study proposed, as a means of mitigating soiling, mounting modules at an angle and anti-reflective coating on glass covers. The status data based on equipment performance monitoring and the control is analyzed and corrective actions proposed. PM is meant to curtail system performance decline and obsolescence risks by minimizing the chances of failure occurrence as well as accelerated components' degradation.

\section{Predictive Maintenance}

With this maintenance method, appropriate mitigation measures are taken (repair or replacement) following the prediction of possible system failure. Remedial actions are performed to forecast and are recommended when maintenance procedures necessary to deal with any incipient failure or fault condition are observed ( $\mathrm{Li}$ et al.,2016). This observation is centered on thorough, continuous, and regular monitoring, supervision, forecast, and performance data on historical performance and anomalies for analysis of the SPV plant (Bosman et al., 2020). The key is in identifying hidden anomalies and irregularities before the next circuit testing or thermal imaging inspection which indicate upcoming component or system failures or underperformance (e.g., at PV modules, inverters, combiner boxes, trackers etc.) (Chebel-Morello et al., 2012; Outline 2015). PdM is a proactive approach that deals with faults and 
TABLE 1 | Summary of types of maintenance strategies.

Maintenance strategy

\section{Corrective maintenance}

Description Reactive approach to faults after returning components to normal functionality

Aim Reparation of failed or faulty conditions

\begin{tabular}{lll} 
Investment & Low initial cost & negligence \\
\hline $\begin{array}{l}\text { Main skill } \\
\text { requirement }\end{array}$ & $\begin{array}{l}\text { Appropriate workmanship for R and R } \\
\text { Troubleshooting and diagnostics }\end{array}$ & Planning and Scheduling \\
\hline Complexity & $\begin{array}{l}\text { Simple: remedial actions are only } \\
\text { carried out after failure occurrence }\end{array}$ & $\begin{array}{l}\text { Moderate: maintenance actions carried in regular } \\
\text { intervals }\end{array}$
\end{tabular}
carried out after failure occurrence

Advantages

- Little planning required

- Suitable for low priority systems with low production sensitivity

Disadvantages

- Maintenance backlog may result

- Production affected by excessive downtime

- Problematic when there are no spare parts and dependence on far away markets

- Pose safety and environmental risks
- Assets' life prolonged

- Less downtime from breakdowns

Routine upkeep actions carried out to maintain equipment in the specified operating condition and prevent accelerated creep

Avoid sudden fault occurrence resulting from

- Inspections are mostly on the good side

- Resources may be strained by unnecessary maintenance actions

\section{Predictive maintenance}

Well anticipated maintenance activities carried out on equipment by analysis of behavioral trends and patterns for unusual performance

Precautious action to resolve any impending malfunctions on the system

High cost

Data control, monitoring, and analytics

Highly complex: maintenance carried out to deal with looming mishaps

- Optimal operation time maximized

- Data captured about components or system condition used for decision making

Cost of software and hardware for implementation are high

- Special skills required for this approach-Machine learning and Al tools

TABLE 2 | Some key sources identifying the various approaches, methods, or strategies for maintenance

\section{Authors}

1 Josh Haney and Adam Burstein

2 Sharma, A., Yadava, G.S. and Deshmukh, S.G.

3 Garg, A. and Deshmukh, S.G.

4 Peinado Gonzalo et al

5 Shafiee, $M$

6 Villarini et al

7 Sanz-Bobi, Miguel A

8 Bosman, Lisa B. Leon-Salas, Walter D., Hutzel, William and Soto, Esteban A

9 Chebel-Morello et al

10 Dehghanian, $\mathrm{P}$ Fotuhi-Firuzabad, M. et al.

11 Dhillon, Balbir S

\section{Title}

PV System Operations and Maintenance Fundamentals

A literature review and future perspectives on maintenance optimization Maintenance management: literature review and directions

Survey of maintenance management for photovoltaic power systems Maintenance strategy selection problem: an MCDM overview Optimization of photovoltaic maintenance plan by means of a FMEA approach based on real data

Use, Operation and Maintenance of Renewable Energy Systems:

Experiences and Future Approaches

PV system predictive maintenance: Challenges, current approaches, and opportunities

E-maintenance for photovoltaic power generation system

A Comprehensive Scheme for Reliability Centered Maintenance in Power Distribution Systems

Engineering systems reliability, safety, and maintenance: An integrated approach
Reference

Haney and Burstein, (2013)

Sharma et al. (2011)

Garg and Deshmukh (2006)

Gonzalo et al. (2020)

Shafiee (2015)

Villarini et al. (2017)

Hatti (2014)

Bosman et al. (2020)

Chebel-Morello et al. (2012)

Dehghanian et al. (2013)

Dhillon (2017)

Literature which Highlights Different approaches or strategies for Solar Photovoltaic Microgrid Systems Maintenance.

failure conditions which target and eliminate symptoms of failure-carried out by integrating analysis, measurement, and periodic test activities.

Choosing which maintenance strategy to adopt for your SPV system is not an easy decision to make; it requires an all-round understanding of the various contributing factors and the special maintenance needs of the system at hand i.e., SPV system.
As shown in Table 1, the choice of maintenance approach is a tough one requiring some balances and tradeoffs to meet the set goals and objectives of the maintenance team. Some key goals include longer system uptime or availability and maximum energy yield. Essentially the first integral and determining factors comes in the form of available resources which are: financial budgets, labor, knowledge and skillset of operators, 
and extent of energy requirement (i.e., is the system serving as backup or main source of power). A good maintenance approach is characterized by a mix and match of the various strategies discussed to get the best benefits of the traits outlined and it is established based on risks and cost-benefit principles, substantiated by literature on Table 2 . The decision here is of critical importance before developing the actual O\&M plan so that tasks of scheduling appropriate skill requirement, predicting future spare part consumption, unequivocal in the maintenance actions, and any specialist work that may need to be outsourced are prepared for.

It is common knowledge that how renewables perform in general is influenced by the environment within which they are deployed. This is the case for SPV systems, and several studies have in the past been undertaken to analyze this key subject area (Awwad et al., 2013; Bouraiou et al., 2015; Bonkaney et al., 2017; Abdalla et al., 2019). Extensive research on the performance of $\mathrm{PV}$ modules installed in the desert region in South of Algeria has also been performed. Taking this into consideration, the operational needs of the particular SPV system are influenced immensely by the type of climate within which it is installed (Mustafa et al., 2020). An O\&M plan must be suited to the environment condition with which the SPV plant in question is installed; this is to be as optimized and cost effective as possible, for instance anti-defrost measures may not be included for SPV systems on hot climates throughout the year.

\section{DEVELOPMENT OF AN OPTIMAL OPERATION AND MAINTENANCE SCHEDULE}

Intervention techniques help in coming up and initiating useful conclusions and conceptions of pro-active plans that ensure the steady functioning of SPV installation, achieved by processing periodic reports' history on productivity and optimal operation (Charki et al., 2017). Developing a maintenance itinerary is an iterative process that involves different stakeholders, who may have conflicting objectives by virtue of their distinct interest and role in a project. The maintenance team try to achieve multiple, and sometimes conflicting, objectives, such as maximizing throughput, availability, and quality, subject to the constraints imposed on the set goals for generation (Labib 1998). Various configurations, control architectures, and modes of operation in SPVM plays a pivotal role in the analysis of maintenance requirements for such systems (Morstyn et al., 2016).

As the solar PV industry progresses, standardized measures and procedures are necessary for the continued dissemination and adaptation of the technology. Literature shows that, ideally, this is achieved in part through a well-founded and instituted O\&M plan (Barberá et al., 2012). There is a need to devise revised and up-to-date strategies as well as execution for the general system upkeep while taking into account the safety, reliability, and planned production (Köntges et al., 2017). Vital information on the reliability of systems and the occurrence of faults is necessary to advise various stakeholders including consumers on the best practices with regards to choice of system components, manufacturer, and appropriate remedial actions and operations procedures (Köntges et al., 2017). As such, it is essential that we quantify the types, locations, and frequency of failures in PV systems installed in the field (Dhoke et al., 2019; Haque et al., 2019).

At the core of this much indispensable exercise is a failure mode and effect analysis FMEA which sets out to, if possible, eliminate the causes of failure or malfunction in solar PV microgrids. In this approach, a well detailed and thorough functional analysis is vital at the outset (Tinga et al., 2020). Even though identification, classification, and diagnosis of faults in SPV systems is still not an easy aspect, strides have been made in this regard. Several studies and pieces of research have been undertaken on both electrical-related, age-related, and performance-related faults developing detection, modelling, and diagnostics techniques (Gokmen et al., 2013; Zhao et al., 2013; Djordjevic et al., 2014; Silvestre et al., 2014; Y.; Zhao et al., 2015; Madeti and Singh 2017). Villarini et al. (2017), carried out an indepth analysis of the various faults, glitches, and failure mechanisms experienced by solar PV installations in the field of work. This study proposes an optimal framework (efficient and cost saving) in the upkeep of solar PV microgrids throughout the design lifespan as well as delivering repair and replacement needs. The subsequent steps are to critically analyze the faults which need an expert eye before finally integrating the proposed solutions/maintenance actions into a schedule (Abu Dabous et al., 2021).

\section{Elements of a Successful Operation and Maintenance Program}

Growth in the deployment of solar PV technologies in aggregate has indirectly resulted in advancement in maintenance practices. Researchers have developed cutting edge technologies and tools for improved and accurate system fault diagnostics, troubleshooting, and prompt remedial actions response by integrating options for document management, technical reporting, fault analysis, maintenance scheduling, and financial reporting (Gilabert and Arnaiz 2006; Efthymiou et al., 2012; Abbassi et al., 2015). O\&M being a heavily technical aspect in solar PV technology is reliant on the size of a system, specific design, and location context. These technicalities cause a variation in maintenance implementation approaches from place to place and the different installation requirements. A maintenance management framework hence is necessary to ensure remedial actions are employed as and when needed to avoid downtime and reduction in service lifetime of the overall system. The key areas with respect to developing an all-round maintenance program are highlighted in Figure 6.

Mgonja, C. T. and Saidi H. undertook a study focusing on offgrid SPV systems in public facilities (Mgonja and Saidi 2017), with a keen eye on maintenance management systems to evaluate effectiveness on its implementation. This evaluation was based on a case study method to propose a model that reflects the need for collective efforts by all relevant stakeholders involved in SPV systems from planning to disposal phase. The proposed model is aimed at improving field maintenance practices by enforcement 
TABLE 3 | Different models for handling operation and maintenance requirements.

O\&M execution model (Epri 2010)

In-house
Description
In this model, the company and or institution owning or hosting the solar PV system
is in charge of ensuring optimal performance and smooth operation and takes care of
any maintenance needs.

Also termed as outsourced to an external contractor, who is charge of the ensuring the client's needs for reliable electricity supply without interruption is met. The contractor carries out any maintenance needs and any system upkeep activities necessary, including warranty claims.

\section{Advantages}

Better Visibility on Personnel/Equipment Issue Improved Quality Control

Ability to Leverage Existing Utility Assets

Workforce training

Company has command of solar PV O\&M Process

Disadvantages

Higher upfront costs

Increased risk

Workforce knowledge/resource ramp up
Third party
Lower Upfront Costs, Greater Flexibility

Lower Upfront risks

Less Drain on Utility Labor Force of active participation by stakeholders in fostering proactive maintenance culture and highlights that failure to swiftly implement a maintenance management scheme in the early project phase has a direct impact on long-term sustainability. In British Standards Institution (BSI, 2010), it is reiterated that, from project conception through to construction, supervision, and inspections as well as commissioning tasks, continual and extended planning is vital for the success of solar PV installation.

Responsibility fragmentation has a direct contribution to the success of O\&M of SPV microgrids. This is possible only if the workflow, from early identification of incipient failure to prompt response by deploying maintenance personnel with the right tools and spare parts, is a combined effort of the asset managers, plant operators, and in-field technicians (Averbukh et al., 2013; Tejwani et al., 2014). As is seen from the Schematic for the main aspects of a maintenance program, the operator is solely involved with O\&M aspects, leaving the microgrid managerial and finance side of operations to the Asset Manager (Palit and Sarangi 2014).As a result, there is assurance of sustainability because of the accountability instilled by this model (approach).

\section{MODELS OF EXECUTING THE OPERATION AND MAINTENANCE PROGRAM}

SPV plants, as capital intensive projects, do require proper management to deal with risks and uncertainties and, most importantly, require someone charged with the responsibility of achieving the project objectives whether economically grounded or centered on energy yield security (C 2010; Gonzalo et al., 2020). The undesirable and faulty running conditions which are usually encountered in the field of operation by solar PV fleets are especially worrisome. While on the quest for improved system reliability and long-term sustainability in solar PV systems, from the operational context an appropriate model of approach should be chosen.
Lack of involvement means no knowledge or skills transfer

Cost may be overinflated

Dependent on outsourced contractors
These models are there to ensure proper enforcement and implementation of the O\&M strategy in-place while presenting and evaluating criteria for success or failure. Executing O\&M can be done through different options, such as Third party O\&M company or inhouse, which are referred to as maintenance management models (Bosman et al., 2020; Solar Power Europe [SPE] 2018).

From Table 3, it is clear that each of the options have varying merits and drawbacks, meaning that a well-grounded decision must be made in selecting the way to pursue plant operation as it will have a huge impact in subsequent good or unwanted aftereffects that may be encountered. A decision-making quandary is presented in the form of risk exposure, labor, upfront and backend costs, quality control, and knowledge capital, prompting logical and sharp resoluteness. For instance, when an organization or company has already existing O\&M related ingredients/resources such as skilled labour, hardware, software, and infrastructure areas, it may be a wise decision to go for an in-house O\&M delivery type of model to cash in on the aforementioned resources. Outsourcing of O\&M is viewed as cost saving, but sometimes it may come as problematic where the contractor compromises quality by using low-end/sub-standard components or spares causing dire effects to the general system operation. A setback may also be brought about by the biasness of the installer to inform the owner of system malfunction or failures, as this may seem to be their fault or poor workmanship (installation and design). Moreover, complications may present when the installers go out of business, rendering any post-installation service, including potential warranty claims, void.

The technicalities of SPV microgrids, as emphasized in the discussions above, necessitates that O\&M needs of the installations should be handled by skilled personnel. This will ensure the system receives prudent management and meets expectations by minimizing risks and uncertainties. The skilled personnel act as operations as well as maintenance practitioners, 
who are engaged by the clients. Their role is to gather data on the ongoing performance and operations on the installations and perform the necessary analysis, diagnosis and troubleshooting, and upkeep measures on the SPV microgrid. The engagements of expatriates to execute the O\&M procedures can be done through two ways, namely In-house or Third-party models, which have merits and shortcomings as underlined in Table 3. However, with the varying objectives and resources, the decision lies at the discretion of the system owner with the guidance of the project development team, with the main goal on protecting the capital investment. The choice is dependent on the system owner's outlook for the installation and application; for instance, a commercial SPV microgrid in an industry that already has a maintenance team may opt for a Hybrid type of model. This pioneering approach for handling the operations and maintenance is one whereby an agreement is made by the system owner and the solar service company to go through a transition period during which there is training and knowledge transfer to the utility/organization's staff. By considering the lifecycle cost of Solar PV installations, this model is a big win for the system owners as there is overall reduction in cost for longer contracts with third-party companies.

\section{CONCLUSION}

SPV is one of the fastest growing renewable energy generation technologies in terms of development and deployment, driven by decreasing levelized costs of electricity and governmental policies like feed-in tariffs. While solar photovoltaic microgrids may intrinsically be low-risk systems as compared to conventional power generation setups, they are subject to unique risks associated with financial, operational, and technical aspects. Unlike standard PV systems, the reliability, safety, and optimal operation of SPV microgrids are improved through the integration of extra protection devices, power conditioning, and modulation electronics. Moreover, the distribution lines across distant consumers and complexity of interconnection networks as shown by the applicable microgrid topologies i.e., radial, ring, and tree architectures, count as further efforts in monitoring, inspection, troubleshooting, and repair requirements. Therefore, an all-inclusive perspective for O\&M and an appropriate basis to show its link to the core of the success of solar PV systems is crucial. This prompts various stakeholders to devise and optimize systems design, operational measures, and maintenance planning and implementation approaches to ensure high system availability, reliability, safety while functioning at a high level of effectiveness, and efficiency. Understanding the various configurations, control architectures, and modes of operation in SPV microgrids plays a pivotal role in the analysis of maintenance requirements for such systems. Moreover, there are different types of challenges

\section{REFERENCES}

Abbassi, R., Khan, F., Garaniya, V., Chai, S., Chin, C., and Hossain, K. A. (2015). An Integrated method for human error probability assessment during the encountered in the field of operation of SPVM which vary depending on installation location, components design, and system optimization goals. Lastly, there is need for a clear maintenance program evaluation and assessment criteria which must show critical metrics to be used by the system as well as the base parameters for comparison and system performance evaluation criteria. Maintenance is an ongoing process, especially in the continuously developing sector of SPV microgrids, hence an O\&M program should be subject to changes if it does not meet the set objectives.

\section{FUTURE WORKS}

Many industries are swiftly transitioning towards operations based on data science and cloud computing; this is also true for solar PV, especially with the idea of benefiting the area of systems operations and dealing with malfunctions and or failure before they occur. Therefore, further studies may be focused on review and analysis of the recent approaches that are based on the application of AI, Machine Learning, and the IoT techniques, their role, and the improvements they bring about in troubleshooting and dealing with remedial actions, especially in SPV systems where failure mechanisms are usually not easily identified with the naked eye. Special attention should be given to the efficacy of the said tools, their economic value addition to the whole benefits of solar PV microgrids, as well as issues of general information security. Because these approaches depend mostly on data collected from systems that are dynamic and may be subject to errors, it will be interesting to portray how the problem presented even in data collection lapses is dealt with and the extent of which is tolerable to work with to achieve reliable diagnostics results. More so than that, we aim to achieve improvement in terms of maintenance management practices, system performance management, and grid stability than the conventional/traditional grid setting.

\section{AUTHOR CONTRIBUTIONS}

All authors listed have made a substantial, direct, and intellectual contribution to the work and approved it for publication.

\section{ACKNOWLEDGMENTS}

The authors acknowledge Innovate UK for the SolaNetwork (Grant reference number: 105280) for this research work was undertaken under the SolaNetwork Project which was granted funding through the "Innovate UK: Energy Catalyst Round 6: Transforming Energy Access Fund".

maintenance of offshore facilities. Process Saf. Environ. Prot. 94, 172-179. doi:10.1016/j.psep.2015.01.010

Abdalla, O., Rezk, H., and Ahmed, E. M. (2019). Wind Driven Optimization Algorithm Based Global MPPT for PV System under Non-Uniform Solar Irradiance. Solar Energy 180 (January), 429-444. doi:10.1016/j.solener.2019.01.056 
Abu Dabous, S., Ibrahim, F., Feroz, S., and Alsyouf, I. (2021). Integration of failure mode, effects, and criticality analysis with multi-criteria decisionmaking in engineering applications: Part I - Manufacturing Industry. Eng. Fail. Anal. 122 (February), 105264. doi:10.1016/ j.engfailanal.2021.105264

Akinyele, D., Belikov, J., and Levron, Y. (2018). Challenges of Microgrids in Remote Communities: A STEEP Model Application. Energies 11 (2), 432-435. doi:10.3390/en11020432

Alam, M. K., Khan, F., Johnson, J., and Flicker, J. (2015). A Comprehensive Review of Catastrophic Faults in PV Arrays: Types, Detection, and Mitigation Techniques. IEEE J. Photovoltaics 5 (3), 982-997. doi:10.1109/ JPHOTOV.2015.2397599

Ali, W., Farooq, H., Rehman, A. U., Awais, Q., Jamil, M., and Noman, A. (2018). Design Considerations of Stand-Alone Solar Photovoltaic Systems. ICE Cube, 2018, 2018 . In 2018 International Conference on Computing, Electronic and Electrical Engineering. doi:10.1109/ ICECUBE.2018.8610970

Allamehzadeh, H. (2016). Solar energy overview and maximizing power output of a solar array using sun trackers. SusTech, 14-19. doi:10.1109/ SusTech.2016.7897136

Argetsinger, B., and Inskeep, B. (2017). Standards and Requirements for Solar Equipment, Installation, and Licensing and Certification A Guide for States and Municipalities SuStainable Solar Education ProjectSustainable Solar Education Project. no. february: 21-35 https://www.cesa.org/assets/2017-Files/Standardsand-Requirements-for-Solar.pdf.

Arsovski, S., Pavlovic, A., Arsovski, Z., Kalinic, Z., and Rankovic, V. (2011). Strategic Approach to Maintenance Management: A Case Study. Strojarstvo 53 (5), 341-352.

Asian Development Bank (2020). Handbook on Microgrids for Power Quality and Connectivity. Metro Manila, Philippines: ADB publications. doi:10.22617/ TIM200182-2

Asuamah, E. Y., Gyamfi, S., and Dagoumas, A. (2021). Potential of Meeting Electricity Needs of Off-Grid Community with Mini-Grid Solar Systems. Scientific Afr. 11 (March), e00675. doi:10.1016/ j.sciaf.2020.e00675

Averbukh, M., Ben-Galim, Y., and Uhananov, A. (2013). Development of a Quick Dynamic Response Maximum Power Point Tracking Algorithm for Off-Grid System with Adaptive Switching (On-Off) Control of Dc/Dc Converter. J. Solar Energ. Eng. Trans. ASME, 135. doi:10.1115/1.4007852

Awwad, R., Shehadeh, M., and Al-SAlaymeh, A. (2013). Experimental Investigation of Dust Effect on the Performance of Photovoltaic Systems in Jordan. Proc. GCREEDER 2013, 10-13. https://www.academia.edu/5486676/ Rund_Awwad_PV_Dust_Effect_Paper_Jordan_2013.

Baklouti, A., Mifdal, L., Dellagi, S., and Chelbi, A. (2020). An Optimal Preventive Maintenance Policy for a Solar Photovoltaic System. Sustainability 12 (10), 4266. doi:10.3390/su12104266

Barberá, L., Crespo, A., Viveros, P., and Stegmaier, R. (2012). Advanced Model for Maintenance Management in a Continuous Improvement Cycle: Integration into the Business Strategy. Int. J. Syst. Assur. Eng. Manag. 3 (1), 47-63. doi:10.1007/s13198-012-0092-y

Baurzhan, S., and Jenkins, G. P. (2016). Off-Grid Solar PV: Is It an Affordable or Appropriate Solution for Rural Electrification in Sub-Saharan African Countries. Renew. Sust. Energ. Rev. 60, 1405-1418. doi:10.1016/ j.rser.2016.03.016

Belhadj-Yahya, C. (2010). "Performance Monitoring of Solar Stand Alone Power Systems," in 2010 IEEE International Energy Conference and Exhibition, EnergyCon 2010, Manama, Bahrain, December 18-22, 2010 (IEEE), 412-416. doi:10.1109/ENERGYCON.2010.5771715

Bhattacharyya, S. C., and Palit, D. (2014). Mini-Grids for Rural Electrification of Developing Countries. Berlin: Green Energy and Technology.

Bonkaney, A., Madougou, S., and Adamou, R. (2017). Impacts of Cloud Cover and Dust on the Performance of Photovoltaic Module in Niamey. J. Renew. Energ. 2017, 8. doi:10.1155/2017/9107502

Bosman, L. B., Leon-Salas, W. D., Hutzel, W., and Soto, E. A. (2020). PV System Predictive Maintenance: Challenges, Current Approaches, and Opportunities. Energies 13 (3), 1398. doi:10.3390/en13061398

Bouraiou, A., Hamouda, M., Chaker, A., Mostefaoui, M., Lachtar, S., Sadok, M., et al. (2015). Analysis and Evaluation of the Impact of Climatic Conditions on the Photovoltaic Modules Performance in the Desert Environment. Energ. Convers. Manag. 106, 1345-1355. doi:10.1016/j.enconman.2015.10.073

Bradford, T. (2006). Solar Revolution: The Economic Transformation of the Global Energy Industry. Massachusetts: MIT Press Books.

British Standards Institution (BSI) (2010). BSI Standards Publication Maintenance - Maintenance Terminology, 36.

Buchholz, B., and Schwaegerl, C. (2004). Advanced Planning and Operation of Dispersed Generation Ensuring Power Quality, Security and Efficiency in Distribution Systems. Paris: CIGRE-Konferenz.

Case, T., and Ketlogetswe, C. (2016). Lessons and Challenges Encountered in the Implementation of Solar Energy - Lessons and Challenges Encountered in the Implementation of Solar Energy - the Case of Botswana. ," no. January 2009. https://doi.org/10.2174/1876387100902010079.

Charki, A., Logerais, P. O., Bigaud, D., Kébé, C. M. F., and Ndiaye, A. (2017). Lifetime Assessment of a Photovoltaic System Using Stochastic Petri Nets. Int. J. Model. Simulation 37 (3), 149-155. doi:10.1080/ 02286203.2017.1297923

Chebel-Morello, B., Medjaher, K., Arab, A. H., Bandou, F., Bouchaib, S., and Zerhouni, N. (2012). E-maintenance for Photovoltaic Power Generation System. Energ. Proced. 18, 640-643. doi:10.1016/j.egypro.2012.05.077

Chine, W., Mellit, A., Pavan, A. M., and Kalogirou, S. A. (2014). Fault Detection Method for Grid-Connected Photovoltaic Plants. Renew. Energ. 66, 99-110. doi:10.1016/j.renene.2013.11.073

Chowdhury, S. A., and Mourshed, M. (2016). Off-Grid Electrification with Solar Home Systems: An Appraisal of the Quality of Components. Renew. Energ. 97, 585-598. doi:10.1016/j.renene.2016.06.017

Dehghanian, P., Fotuhi-Firuzabad, M., Aminifar, F., and Billinton, R. (2013). A Comprehensive Scheme for Reliability Centered Maintenance in Power Distribution Systems-Part I: Methodology. IEEE Trans. Power Deliv. 28 (2), 761-770. doi:10.1109/TPWRD.2012.2227832

Deli, K., and Noel, D. (2020). On-Field Operation and Maintenance of Photovoltaic Systems in Cameroon. Maintenance Manag. doi:10.5772/ intechopen. 83730

Dhillon, B. (2017). Engineering Systems Reliability, Safety, and Maintenance. Eng. Syst. Reliability, Saf. Maintenance: Integrated Approach. doi:10.1201/ 9781315160535

Dhillon, B. S. (2002). Engineering Maintenance. Eng. Maintenance. doi:10.1201/ 9781420031843

Dhimish, M., Holmes, V., and Dales, M. (2017). Parallel Fault Detection Algorithm for Grid-Connected Photovoltaic Plants. Renew. Energ. 113, 94-111. doi:10.1016/j.renene.2017.05.084

Dhoke, A., Sharma, R., and Saha, T. K. (2019). An Approach for Fault Detection and Location in Solar PV Systems. Solar Energy 194 (November), 197-208. doi:10.1016/j.solener.2019.10.052

Djordjevic, S., Parlevliet, D., and Jennings, P. (2014). Detectable Faults on Recently Installed Solar Modules in Western Australia. Renew. Energ. 67, 215-221. doi:10.1016/j.renene.2013.11.036

Drews, A., de Keizer, A. C., Beyer, H. G., Lorenz, E., Betcke, J., van Sark, W. G. J. H. M., et al. (2007). Monitoring and Remote Failure Detection of Grid-Connected PV Systems Based on Satellite Observations. Solar Energy 81, 548-564. doi:10.1016/j.solener.2006.06.019

Duttagupta, S. S., and Singh., C. (2006). A Reliability Assessment Methodology for Distribution Systems with Distributed Generation. PES, 1, 2006 . " 2006 IEEE Power Engineering Society General Meeting-7. doi:10.1109/ pes.2006.1708964

Efthymiou, K., Papakostas, N., Mourtzis, D., and Chryssolouris, G. (2012). On a Predictive Maintenance Platform for Production Systems. Proced. CIRP 3, 221-226. doi:10.1016/j.procir.2012.07.039

Eltawil, M. A., and Zhao., Z. (2010). Grid-Connected Photovoltaic Power Systems: Technical and Potential Problems-A Review. Renew. Sust. Energ. Rev. 14 (1), 112-129. doi:10.1016/j.rser.2009.07.015

Emblemsvåg, J. (2020). On the Levelised Cost of Energy of Solar Photovoltaics. Int. J. Sust. Energ. 40, 755-780. doi:10.1080/14786451.2020.1867139

Epri (2010). "Addressing Solar Photovoltaic Operations and Maintenance Challenges." Challenges. July: 22 http://www.smartgridnews.com/artman/ uploads/1/1021496AddressingPVOaMChallenges7-2010_1_.pdf.

Forum, Economic (2020). The Role of Standards in Modern Solar Power London, United Kingdom: British Standards Int. 
Garg, A., and Deshmukh, S. G. (2006). Maintenance Management: Literature Review and Directions. J. Qual. Maintenance Eng. 12 (3), 205-238. doi:10.1108/ 13552510610685075

Gilabert, E., and Arnaiz, A. (2006). Intelligent Automation Systems for Predictive Maintenance: A Case Study. Robotics and Computer-Integrated Manufacturing 22, 543-549. doi:10.1016/j.rcim.2005.12.010

Global Sustainable Energy Solutions [GSES] (2017). Installation, Operation \& Maintenance of Solar PV Microgrid Systems. http://isolaralliance.org/docs/ Microgrid-Trainers-Handbook.pdf.

Gokmen, N., Karatepe, E., Celik, B., and Silvestre, S. (2012). Simple Diagnostic Approach for Determining of Faulted PV Modules in String Based PV Arrays. Solar Energy 86 (11), 3364-3377. doi:10.1016/ j.solener.2012.09.007

Gokmen, N., Karatepe, E., Silvestre, S., Celik, B., and Ortega, P. (2013). An Efficient Fault Diagnosis Method for PV Systems Based on Operating Voltage-Window. Energ. Convers. Manag. 73, 350-360. doi:10.1016/ j.enconman.2013.05.015

Goswami, Y., and Kreider, J. F. (2001). "Photovoltaic Systems." in Distributed Generation: The Power Paradigm For the New Millennium, Editors J. F. Kreider and A. M. Borbely (Boca Raton, FL: CRC/Taylor and Francis). doi:10.5822/9781-61091-821-3_11

Haney, J., and Burstein, A. (2013). PV System Operations and Maintenance Fundamentals SolarSolarABCs, no. August. www.solarabcs.org.

Haque, A., Bharath, K. V. S., Khan, M. A., Khan, I., and Jaffery, Z. A. (2019). Fault Diagnosis of Photovoltaic Modules. Energy Sci Eng 7 (3), 622-644. doi:10.1002/ ese3.255

Harrou, F., Taghezouit, B., and Sun, Y. (2019). Robust and Flexible Strategy for Fault Detection in Grid-Connected Photovoltaic Systems. Energ. Convers. Manag. 180 (December 2018), 1153-1166. doi:10.1016/j.enconman.2018.11.022

Hatti, M. (2014). "Use, Operation and Maintenance of Renewable Energy Systems: Experiences and Future Approaches." In Use, Operation and Maintenance of Renewable Energy Systems: Experiences and Future Approaches. Editors M. A. Sanz-Bobi (London, United Kingdom: Springer International Publishing), 61-94. doi:10.1007/978-3-319-03224-5

Hernández-Callejo, L., Gallardo-Saavedra, S., and Alonso-Gómez, V. (2019). A Review of Photovoltaic Systems: Design, Operation and Maintenance. Solar Energy 188, 426-440. doi:10.1016/j.solener.2019.06.017

Hirsch, A., Parag, Y., and Guerrero, J. (2018). Microgrids: A Review of Technologies, Key Drivers, and Outstanding Issues. Renew. Sust. Energ. Rev. 90 (September 2017), 402-411. doi:10.1016/j.rser.2018.03.040

Iftikhar, H., Sarquis, E., and Branco, P. J. C. (2021). Why Can Simple Operation and Maintenance (O\&M) Practices in Large-Scale Grid-Connected PV Power Plants Play a Key Role in Improving Its Energy Output. Energies 14 (13), 3798. doi:10.3390/en 14133798

Imene Yahyaoui University Carlos III of Madrid (2018). Advances in Renewable Energies and Power Technologies. Spain: IYUC.

International Renewable Energy Agency - IRENA (2019). Future of Solar Photovoltaic. Irena. Vol. November. https:/www.irena.org/-/media/Files/ IRENA/Agency/Publication/2019/Oct/IRENA_Future_of_wind_2019.pdf.

Jahn, U. (2003). Performance, Reliability and User Experience. Pract. Handbook Photovoltaics: Fundamentals Appl., 749-770. doi:10.1016/B978-185617390-2/ 50032-5

Justo, J. J., Mwasilu, F., Lee, J., and Jung, J. W. (2013). AC-Microgrids versus DCMicrogrids with Distributed Energy Resources: A Review. Renew. Sustain. Energy Rev. 24, 387-405. doi:10.1016/j.rser.2013.03.067

Kale, S. A. (2016). Renewable Energy Systems. Renew. Energ. Syst. doi:10.1007/9781-4899-6870-8_28

Kandpal, M., Hussain, I., and Singh, B. (2016). $I^{*}, 1-6$.

Katiraei, F., Mauch, K., and Dignard-Bailey, L. (2007). Integration of Photovoltaic Power Systems in High-Penetration Clusters for Distribution Networks and Mini-Grids. Int. J. Distributed Energ. Resour. 3 (3), 207-223.

Köntges, M., Oreski, G., Jahn, U., Herz, M., Peter, H., Weiss, K., et al. (2017). Assessment of Photovoltaic Module Failures in the Field. Report IEA-PVPS T1309:2017 http://www.iea-pvps.org/index.php?id=92\&eID=dam_frontend_ push\&docID $=4059$.

Kumar, D., Zare, F., and Ghosh, A. (2017). DC Microgrid Technology: System Architectures, AC Grid Interfaces, Grounding Schemes, Power Quality,
Communication Networks, Applications, and Standardizations Aspects. IEEE Access 5 (August), 12230-12256. doi:10.1109/ACCESS.2017.2705914

Kumar, D., Zare, F., and Gosh, A. (2017). DC Microgrid Technology: System Architectures, AC Grid Interfaces, Grounding Schemes, Power Quality, Communication Networks, Applications, and Standardizations Aspects. IEEE 5, 12230-12256. doi:10.1109/ACCESS.2017.2705914

Labib, A. W. (1998). World-class maintenance using a computerised maintenance management system. J. Qual. Maintenance Eng. 4 (1), 66-75. doi:10.1108/ 13552519810207470

Li, Z., Wang, K., and He, Y. 2016, "Industry 4.0 - Potentials for Predictive Maintenance," in, Editors Y. Wang, K. Wang, J. O. Strandhagen, and T. Yu (Amsterdam, Netherlands: Atlantis Press)doi:10.2991/iwama-16.2016.8

Louie, H. (2018). Henry Louie.

Lynn, K. (2005). "Procedures for Photovoltaic System Design Review and Approval," in Conference Record of the IEEE Photovoltaic Specialists Conference, Lake Buena Vista, FL (IEEE). doi:10.1109/PVSC.2005.1488495

Machrafi, H. (2012). Green Energy and Technology. Green. Energ. Tech. doi:10.2174/97816080528511120101

Madeti, S. R., and Singh, S. N. (2017). A Comprehensive Study on Different Types of Faults and Detection Techniques for Solar Photovoltaic System. Solar Energy 158, 161-185. doi:10.1016/j.solener.2017.08.069

Majumder, R. (2013). Some Aspects of Stability in Microgrids. IEEE Trans. Power Syst. 28 (3), 3243-3252. doi:10.1109/TPWRS.2012.2234146

Makala, B., and Bakovic, T. (2020). Artificial Intelligence in the Power Sector. Int. Finance Corporation 1-8. https://www.ifc.org/wps/wcm/connect/bd3a196d-a88f45af-bbc6-e0b00790fba8/EMCompass_Note_81-05-web.pdf?MOD=AJPERES\&CVID $=\mathrm{n} 72 \mathrm{pj} 5 \mathrm{~g}$.

Marnay, C., Chatzivasileiadis, S., Abbey, C., Iravani, R., Joos, G., Lombardi, P., et al. (2015). Microgrid Evolution Roadmap. EDST, 139-144. doi:10.1109/ SEDST.2015.7315197

Messenger, R., and Yogi Goswami, D. (2015). "Energy Efficiency and Renewable Energy Handbook," in Energy Efficiency and Renewable Energy: Handbook. Second Edition, Editors D. Frank Kreith and Y. Gowsami (Boca Ratton, London, New York: CRC Press/ Taylor and Francis Group). doi:10.1201/b18947

Mgonja, C. T., and Hamisi, S. (2017). Effectiveness on Implementation of Maintenance Management System for Off-Grid Solar Pv Systems in Public Facilities - A Case Study of Ssmp1 Project in Tanzania. Int. J. Mech. Eng. Tech. 8 (7), 869-880.

Myeni, M. (2019). Operation and Maintenance Manual for Okyereko Eswatini: WaterAid.

Morstyn, T., Hredzak, B., and Agelidis, V. G. (2018). Control Strategies for Microgrids with Distributed Energy Storage Systems: An Overview. IEEE Trans. Smart Grid 9 (4), 3652-3666. doi:10.1109/ TSG.2016.2637958

Muñoz-Cerón, E., Lomas, J. C., Aguilera, J., and de la Casa, J. (2018). Influence of Operation and Maintenance Expenditures in the Feasibility of Photovoltaic Projects: The Case of a Tracking Pv Plant in Spain. Energy Policy 121 (December 2017), 506-518. doi:10.1016/j.enpol.2018.07.014

Mustafa, R. J., Gomaa, M. R., Al-Dhaifallah, M., and Rezk, H. (2020). Environmental Impacts on the Performance of Solar Photovoltaic Systems. Sustainability 12 (2), 608-617. doi:10.3390/su12020608

National Renewable Energy Laboratory (NREL) (2018). "Best Practices for Operation and Maintenance of Photovoltaic and Energy Storage Systems. 3rd Edition. Nrel/Tp-7a40-73822, no. December: 153 https://www.nrel.gov/ research/publications.html.

Njoh, A. J., Etta, S., Ngyah-Etchutambe, I. B., Enomah, L. E. D., Tabrey, H. T., and Essia, U. (2019). Opportunities and Challenges to Rural Renewable Energy Projects in Africa: Lessons from the Esaghem Village, Cameroon Solar Electrification Project. Renew. Energ. 131, 1013-1021. doi:10.1016/ j.renene.2018.07.092

Opiyo, N. N. (2019a). A Comparison of DC- versus AC-Based Minigrids for CostEffective Electrification of Rural Developing Communities. Energ. Rep. 5, 398-408. doi:10.1016/j.egyr.2019.04.001

Opiyo, N. N. (2019b). A Comparison of DC- versus AC-Based Minigrids for CostEffective Electrification of Rural Developing Communities. Energ. Rep. 5, 398-408. doi:10.1016/j.egyr.2019.04.001

Oprea, S.-V., Bara, A., Preotescu, D., and Elefterescu, L. (2019). Photovoltaic Power Plants (PV-PP) Reliability Indicators for Improving Operation and 
Maintenance Activities. A Case Study of PV-PP Agigea Located in Romania. IEEE Access 7, 39142-39157. doi:10.1109/ACCESS.2019.2907098

Osmani, K., Haddad, A., Lemenand, T., Castanier, B., and Ramadan, M. (2020). A Review on Maintenance Strategies for PV Systems. Sci. Total Environ. 746, 141753. doi:10.1016/j.scitotenv.2020.141753

Outline, C. (2015). Systems Maintenance and Reliability. Eng. Syst. Acquisition Support, 139-152. doi:10.1016/b978-0-85709-212-0.00008-0

Palit, D., and Sarangi, G. K. 2014. "Renewable Energy Based Mini-Grids for Enhancing Electricity Access: Experiences and Lessons from India." Proceedings of the 2014 International Conference and Utility Exhibition on Green Energy for Sustainable Development, ICUE 2014, no. March: 19-21.

Par, H., Son, J., and Rho, D. (2009). "Optimal Method for Mal-Function for Protective Devices in Distribution Systems Interconnected with PV Systems," in 2009 Transmission \& Distribution Conference \& Exposition: Asia and Pacific, 1. -4. doi:10.1109/TD-ASIA.2009.5356886

Paul, E., and Bray, D. (2012). Evolution of Solar Operating Practices: Advanced OßM Benefits from Module-Level Monitoring Solution Deployment Brief Evolution of Solar Operating Practices: Advanced O\&M Benefits from Module-Level Monitoring. Los Altos, CA: AltaTerra Research. " no. May.

Peinado Gonzalo, A., Pliego Marugán, A., García Márquez, F. P., and Márquez, F. P. G. (2020). Survey of Maintenance Management for Photovoltaic Power Systems. Renew. Sust. Energ. Rev. 134 (March), 110347. doi:10.1016/j.rser.2020.110347

Said, S. A. M., and Walwil, H. M. (2014). Fundamental Studies on Dust Fouling Effects on PV Module Performance. Solar Energy 107, 328-337. doi:10.1016/ j.solener.2014.05.048

Salman, S., Xin, A., Masood, A., Iqbal, S., Hanan, M., Jan, M. U., et al. (2018). "Design and Implementation of Surge Protective Device for Solar Panels." In 2018Energy Internet Energ. Syst. Integration (EI2), 1-6. doi:10.1109/ EI2.2018.8582097

Schnitzer, D., Shinde, D., Carvallo, J., Deshmukh, R., Apt, J., Daniel, M. K., et al. (2014). "Microgrids for Rural Electrification: A Critical Review of Best Practices," Berkeley, CA: United Nations Foundation. doi:10.13140/RG.2.1.1399.9600

Sebitosi, A. B., Pillay, P., and Khan, M. A. (2006). An Approach to Rural Distribution Network Design for Sub-Saharan Africa. Energ. Convers. Manag. 47 (9-10), 1101-1112. doi:10.1016/j.enconman.2005.07.008

Shafiee, M. (2015). Maintenance Strategy Selection Problem: An MCDM Overview. J. Qual. Maintenance Eng. 21 (4), 378-402. doi:10.1108/JQME09-2013-0063

Sharma, A., Yadava, G. S., and Deshmukh, S. G. (2011). A Literature Review and Future Perspectives on Maintenance Optimization. J. Qual. Maintenance Eng. 17 (1), 5-25. doi:10.1108/13552511111116222

Sharma, V., and Chandel, S. S. (2013). Performance and Degradation Analysis for Long Term Reliability of Solar Photovoltaic Systems: A Review. Renew. Sust. Energ. Rev. 27, 753-767. doi:10.1016/j.rser.2013.07.046

Silvestre, S., Silva, M. A. d., Chouder, A., Guasch, D., and Karatepe, E. (2014). New Procedure for Fault Detection in Grid Connected PV Systems Based on the Evaluation of Current and Voltage Indicators. Energ. Convers. Manag. 86, 241-249. doi:10.1016/j.enconman.2014.05.008

Solar Power Europe [SPE] (2018). Operation \& Maintenance Best Practices Guidelines/Version 3.0. Solar Power Europe, 56-60. www. solarpowereurope.org.

Solar System Safety and Maintenance." 2011. New York, NY: NABCEP UK, 1-20.

Starr, A., Al-Najjar, B., Holmberg, K., Jantunen, E., Bellew, J., and Albarbar, A. (2010). Maintenance Today and Future Trends. E-Maintenance, 5-37. doi:10.1007/978-1-84996-205-6_2

Tahri, A., Oozeki, T., and Draou, A. (2013). Monitoring and Evaluation of Photovoltaic System. Energ. Proced. 42, 456-464. doi:10.1016/ j.egypro.2013.11.046

Tejwani, R., Kumar, G., and Solanki, C. (2014). Remote Monitoring for Solar Photovoltaic Systems in Rural Application Using GSM Voice
Channel. Energ. Proced. 57 (1959), 1526-1535. doi:10.1016/ j.egypro.2014.10.145

Thangaraj, S., and Velury, M. (2016). Importance of Operations and Maintenance in a Solar PV System. Imperial J. Interdiscip. Res. (Ijir) Great Lakes Inst. Manag. Gurgaon, India 2, 4.

Tinga, T., Wubben, F., Tiddens, W., Wortmann, H., and Gaalman, G. (2020). Dynamic Maintenance Based on Functional Usage Profiles. Jqme 27 (1), 21-42. doi:10.1108/JQME-01-2019-0002

United States Agency for International Development. 2013. "Solar Pv System Maintenance Guide: Guyana Hinterlands Stand-Alone. Solar Pv," no. April: 12. doi: $10.1038 / \mathrm{nn} .2900$

Van Horenbeek, A., Scarf, P. A., Cavalcante, C. A. V., and Pintelon, L. (2013). The Effect of Maintenance Quality on Spare Parts Inventory for a Fleet of Assets. IEEE Trans. Rel. 62 (3), 596-607. doi:10.1109/TR.2013.2270409

Ventura, C., and Tina, G. M. (2016). Utility Scale Photovoltaic Plant Indices and Models for On-Line Monitoring and Fault Detection Purposes. Electric Power Syst. Res. 136, 43-56. doi:10.1016/j.epsr.2016.02.006

Villarini, M., Cesarotti, V., Alfonsi, L., and Introna, V. (2017). Optimization of Photovoltaic Maintenance Plan by Means of a FMEA Approach Based on Real Data. Energ. Convers. Manag. 152 (May), 1-12. doi:10.1016/j.enconman.2017.08.090

Wireman, T. (2015). Benchmarking Best Practices in Maintenance, Reliability and Asset Management. New York: Industrial Press, Inc. Updated for ISO 55000 .

Woyte, A., and Goy, S. (2017). "Large grid-connected photovoltaic power plants," in The Performance of Photovoltaic (PV) Systems: Modelling, Measurement and Assessment (Tharamani: Elsevier), 321-337. doi:10.1016/B978-1-78242-3362.00011-2

Yang, J., Fu, L., and Yu, Y.-h. (2014). Research on Experiment of Islanding Protection Device of Grid-Connected Photovoltaic System Base on RTDS. Electricity Distribution (CICED), 114-118. In 2014 China International Conference on. doi:10.1109/CICED.2014.6991676

Zhao, B., Wang, C., and Zhang, X. (2017). Grid-Integrated and Standalone Photovoltaic Distributed Generation Systems. Grid-Integrated Standalone Photovoltaic Distributed Generation Syst. doi:10.1002/ 9781119187349

Zhao, Y., Ball, R., Mosesian, J., de Palma, J.-F., Lehman, B., and Lehman, B. (2015). Graph-Based Semi-Supervised Learning for Fault Detection and Classification in Solar Photovoltaic Arrays. IEEE Trans. Power Electron. 30, 2848-2858. doi:10.1109/TPEL.2014.2364203

Zhao, Y., De Palma, J.-F., Mosesian, J., Lyons, R., and Lehman, B. (2013). Line-Line Fault Analysis and Protection Challenges in Solar Photovoltaic Arrays. IEEE Trans. Ind. Elect. 60, 3784-3795. doi:10.1109/ TIE.2012.2205355

Conflict of Interest: The authors declare that the research was conducted in the absence of any commercial or financial relationships that could be construed as a potential conflict of interest.

Publisher's Note: All claims expressed in this article are solely those of the authors and do not necessarily represent those of their affiliated organizations, or those of the publisher, the editors and the reviewers. Any product that may be evaluated in this article, or claim that may be made by its manufacturer, is not guaranteed or endorsed by the publisher.

Copyright $\odot 2021$ Keisang, Bader and Samikannu. This is an open-access article distributed under the terms of the Creative Commons Attribution License (CC BY). The use, distribution or reproduction in other forums is permitted, provided the original author(s) and the copyright owner(s) are credited and that the original publication in this journal is cited, in accordance with accepted academic practice. No use, distribution or reproduction is permitted which does not comply with these terms. 